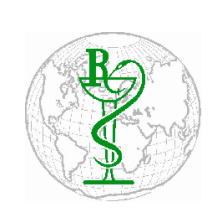

INDO GLOBAL JOURNAL OF

PHARMACEUTICAL SCIENCES

ISSN 2249- 1023

\title{
Response of Plant Growth Promoting Rhizobacteria (PGPR) in Relation to Elevated Temperature Conditions in Ground Nut (Arachis hypogaea L.)
}

\author{
Sweta Kachhap * \\ Centre for Environment Science \& Climate Resilient Agriculture (CESCRA), IARI, New Delhi-110012, India
}

Address for Correspondence: Sweta Kachhap; swetakachhap123@gmail.com

\begin{abstract}
The elevated temperature conditions are also likely to modify the ecosystem functioning including the role of various Plant Growth Promoting Rhizobacteria (PGPR), which are directly dependent on rhizodepostion. The impact of temperature in the present and future climate change scenarios on some PGPR populations in rhizosphere soil of groundnut was investigated. Groundnut variety B-95 was planted with four treatments of temperature. Rhizosphere soil samples were collected at the vegetative, flowering, pod development and maturity stages of groundnut. Various strains of Pseudomonas spp., Enterobacter spp., Azotobacter spp. and Acetobacter spp. at different stages of crop growth were enumerated, isolated and tested for several PGP traits such as IAA, siderophore etc. The data presented here showed consistent statistically significant differences in the numbers of different groups of functional bacteria between rhizosphere soil from ambient and above ambient temperature treatments from germination to maturity. The rhizobacterial isolates represented Pseudomonas (25.3\%), Azotobacter (16.5\%), Acetobacter (15.2\%) and Enterobacter (21.5\%) population. 73.4\% of the total isolates were able to produce IAA whereas $70.9 \%$ of the total isolates were positive for $\mathrm{NH}_{3}$ production. Pseudomonas spp. were strong at exhibiting protease activity with $75 \%$ of isolates as test positive. 42 and 49 strains could display antagonism for A. niger and F. moniliforme respectively. No loss or gain of PGP traits as a result of temperature could be seen. The effect of their population and exhibition of PGP traits were correlated with the plant height, root length, root dry weight and no. of nodules. (C) 2014 iGlobal Research and Publishing Foundation. All rights reserved.
\end{abstract}

Conference Proceedings: International Conference on Life Sciences, Informatics, Food and Environment; August 29- 30, 2014

Indo Global Journal of Pharmaceutical Sciences( ISSN 22491023 ; CODEN- IGJPAI; NLM ID: 101610675) indexed and abstracted in EMBASE(Elsevier), SCIRUS(Elsevier),CABI, CAB Abstracts, Chemical Abstract Services(CAS), American Chemical Society(ACS), Index Copernicus, EBSCO, DOAJ, Google Scholar and many more. For further details, visit 